\title{
Innate Immune Markers in Mothers and Fathers of Children Newly Diagnosed with Cancer
}

\author{
Meredith J. Lutz Stehl ${ }^{a}$ Anne E. Kazak ${ }^{a, b}$ Wei-Ting Hwang ${ }^{c}$ Ahna L.H. Pai ${ }^{a}$ \\ Anne F. Reilly ${ }^{a}$ b Steven D. Douglas ${ }^{d}$ \\ a Division of Oncology, The Children's Hospital of Philadelphia, Departments of ${ }^{b}$ Pediatrics and \\ 'Biostatistics and Epidemiology, University of Pennsylvania School of Medicine, and d Division of Allergy-Immunology, \\ The Joseph Stokes Jr. Research Institute at The Children's Hospital of Philadelphia, Philadelphia, Pa., USA
}

\section{Key Words}

Pediatric cancer $\cdot$ Natural killer cell $\cdot$ Immune function .

Caregivers $\cdot$ Acute stress

\begin{abstract}
Objective: The diagnosis of a life-threatening illness in a child is one of the most stressful events imaginable for parents and is associated with increased anxiety and distress. Despite associations between stress and immune function in animal and human models, the immune function in caregivers of children at the time of a child-related potentially traumatic event, like cancer, is not known. Methods: Nineteen parents ( 11 mothers, 8 fathers), representing six caregiver pairs, provided blood for natural killer (NK) cell count by flow cytometry and function assays [\% NK whole blood, absolute NK whole blood, $\mathrm{LU}_{20}$ (lytic unit) peripheral blood mononuclear cells, $\mathrm{LU}_{20} \mathrm{NK}$ cells] and completed self-report measures (acute stress) within 2 weeks of learning their child had cancer. The NK cell assay was also completed with a sample of healthy adults, the immune reference group. Results: There were similar levels of NK cell activity between caregivers and the immune reference group. Immune level and psychological outcomes were not associated. $\mathrm{LU}_{20}$ peripheral blood mononuclear cells and $\mathrm{LU}_{20} \mathrm{NK}$ cells were each corre-
\end{abstract}

lated at $r=0.83$ between mothers and fathers in the same family. Conclusions: Although based on a small sample, these preliminary results suggest that knowledge about stress responses in parents of children with life-threatening illness may be important and provide novel data regarding the shared impact of stress on immune function within caregiver dyads.

Copyright $\odot 2008$ S. Karger AG, Basel

\section{Introduction}

The receipt of information by a parent that a child has a life-threatening illness is a potentially traumatic event $[1,2]$ associated with elevated anxiety and distress [3]. Slightly over half of mothers and two thirds of fathers met diagnostic criteria for Acute Stress Disorder (ASD) [4] when assessed within 2 weeks of their child's cancer diagnosis [5]. While psychologically noteworthy, the potential impact of this stress on parents' immune function is not known.

In other populations, stressors associated with serious illness are associated with decreased innate immune function, including natural killer (NK) cell activity (as measured by NK cell lysis). These include adults prepar-

\section{KARGER \\ Fax +41613061234 E-Mail karger@karger.ch} www.karger.com
(C) 2008 S. Karger AG, Basel $1021-7401 / 08 / 0152-0102 \$ 24.50 / 0$

Accessible online at: www.karger.com/nim
Dr. Anne E. Kazak

The Children's Hospital of Philadelphia

34th Street and Civic Center Boulevard, Room 1486, CHOP North

Philadelphia, PA 19104-4399 (USA)

Tel. +1 215590 2220, Fax +1 215590 3020,E-Mail kazak@email.chop.edu 
ing for surgery [6] and individuals with cancer [7] and HIV [8]. Nurses experiencing high levels of professional stress have also been found to demonstrate impaired immunity [9]. Impairment in immune function is associated with depression, posttraumatic stress disorder and anxiety $[10,11]$, problems also noted in parents of children with cancer. Stress associated with caregiving for a child with a life-threatening medical condition has been associated with impaired NK cell function [12-14]; however, the impact of such stress on the parental dyad is less well understood, but important in conceptualizing stress from a biopsychosocial perspective.

The goals of this preliminary report were: (1) to describe innate immune function in mothers and fathers shortly after the diagnosis of cancer in their child; (2) to examine relationships between innate immune function (NK cell activity) and traumatic stress, and (3) to explore innate immune function within mother-father dyads.

\section{Materials and Methods}

\section{Subjects and Procedures}

Caregivers of children newly diagnosed with a pediatric malignancy were approached to participate in an Institutional Review Board-approved randomized clinical trial (RCT) of a cognitive-behavioral and family therapy intervention [1]. Two caregivers for each child were required. Caregivers were excluded from the study if the child's treatments did not involve chemotherapy or radiation, if treatments were provided at another hospital, if the child had been diagnosed more than 1-2 months before, if the child had a comorbid medical and/or psychiatric illness and/or was referred for palliative care at diagnosis, or if the caregiver lacked fluency in English. When informed consent was obtained, all caregivers were given the option to participate in a portion of the study that evaluated immunity.

Nineteen caregivers (11 mothers, 8 fathers), representing six caregiver pairs, consented to the phlebotomy required for this part of the study out of a total of 152 caregivers who consented to the RCT. Caregivers generally consented to participate in the study 1-2 weeks after their child's diagnosis (mean = 12.3 days, $\mathrm{SD}=7.7$ days). Data collection, including venipuncture, took place approximately 2 weeks after diagnosis (mean $=17.9$ days, $\mathrm{SD}=10.6$ days) and prior to randomization for the RCT.

While participants completed self-report measures of acute stress, $20 \mathrm{~cm}^{3}$ of blood was drawn by nurses from the Clinical and Translational Research Center to measure NK cell number and function. Participants also completed a brief questionnaire about their general health. Caregivers completed a portion of the selfreport questionnaires immediately prior to the blood draw and then finished questionnaires after the blood draw.

Forty-six healthy adults, the immunity reference group (IRG), were used to establish ranges for the immune variables and served as a comparison group for the immune variables. The IRG consisted of 27 females and 18 males. Data from the IRG were gathered prior to the beginning of the immunity study and data collection continued throughout the study. The psychological reference group (PRG) consisted of 128 caregivers of children recently diagnosed with cancer, drawn from the same sample. The data from the PRG established ranges for the psychological variables. Consent was obtained from all participants and study protocols were approved by the Institutional Review Board.

\section{Measures}

Acute and Posttraumatic Stress

Acute Stress Disorder Scale (ASDS). The ASDS [15] is used to assess acute parental stress reactions to diagnosis and has been used in a number of studies evaluating acute stress reactions of caregivers $[16,17]$. Nineteen items are rated on a 5-point scale according to the extent to which each symptom is present $(1=$ not at all, 5 = very much). Items are summed to obtain an overall score, with higher scores reflecting greater distress. Total scores over 56 are indicative of ASD [15]. The ASDS demonstrated excellent internal consistency in the current sample $(\alpha=0.93)$.

\section{Medical Intensity}

The Intensity of Treatment Rating Scale. The second edition of this scale [18] provides a four-level categorization of the intensity of pediatric cancer treatment, based on oncologist ratings of the patient's disease and treatment protocol. Two pediatric oncologists provided blinded ratings for the patients in this study. Interrater reliability was 1.0 for this sample and 0.96 for the PRG.

Health Screening Questionnaire

The Health Screening Questionnaire was designed for this study and consisted of five questions about major illnesses, steroid use, hospitalization and/or surgery over the past 2 months, blood transfusion in the past week, and chemotherapy in the past year.

Natural Killer Cells

NK cells were enumerated by a three-color flow cytometry and percentage of NK cells was determined as described previously [8]. The markers used included the percentage of CD3-/ CD16+/CD56+ cells, which were considered to be the predominant population of NK cells. The functional capability of NK cells is determined using a known NK-specific target. NK cell activity is quantified in this assay by using the $\mathrm{K} 562$ cell line as a target, which is incubated for $1 \mathrm{~h}$ with chromium-51. The targets are then incubated with different serial dilutions of peripheral blood mononuclear cells (PBMCs; effectors) for $4 \mathrm{~h}$ at $37^{\circ} \mathrm{C}$ in a 96 -well plate. The effectors lyse the target cells, releasing chromium-51 into the media. At the end of the incubation, the plate is centrifuged and the supernatants are collected. The amount of chromium-51 released into these supernatants, which is measured with a TopCount liquid scintillation counter, can be used to determine the lytic capability of the NK cells at each effector:target ratio. $\mathrm{LU}_{20}$ (lytic unit) $\mathrm{PBMC}$ and $\mathrm{LU}_{20} \mathrm{NK}$ are the numbers of effector cells required to achieve $20 \%$ lysis of target cells per $10 \mathrm{mil}-$ lion PBMC or 10 million NK cells $[8,19]$.

Data Analysis

Descriptive statistics were run on sample demographic variables (child diagnosis, caregiver age, ethnicity, marital status, education, income) and psychosocial outcome variables (acute stress). 
Table 1. Demographics of immunity and PRG samples

\begin{tabular}{|c|c|c|c|c|}
\hline & Mothers' immunity & Mothers' PRG & Fathers' immunity & Fathers' PRG \\
\hline Number of patients & 11 & 65 & 8 & 63 \\
\hline Age, years (mean $\pm S D)$ & $35.8 \pm 7.5$ & $36.4 \pm 6.3$ & $39.1 \pm 4.6$ & $40.3 \pm 9.8$ \\
\hline Married & $7(70 \%)$ & $55(85 \%)$ & $8(100 \%)$ & $51(81 \%)$ \\
\hline High school diploma & $10(91 \%)$ & $61(94 \%)$ & $8(100 \%)$ & $61(97 \%)$ \\
\hline \multicolumn{5}{|l|}{ Ethnicity } \\
\hline White & $8(73 \%)$ & $49(78 \%)$ & $7(87.5 \%)$ & $48(78.5 \%)$ \\
\hline Black & $2(18 \%)$ & $5(8 \%)$ & & $6(10 \%)$ \\
\hline Asian & $1(9 \%)$ & $5(8 \%)$ & $1(12.5 \%)$ & $4(6.5 \%)$ \\
\hline Hispanic & 0 & $4(6 \%)$ & & $3(5 \%)$ \\
\hline \multicolumn{5}{|l|}{ Income level, USD } \\
\hline$<50,000$ & $6(55 \%)$ & $11(18 \%)$ & $2(25 \%)$ & $11(18 \%)$ \\
\hline $50-99,999$ & $2(18 \%)$ & $20(33 \%)$ & $2(25 \%)$ & $22(35 \%)$ \\
\hline$>100,000$ & $3(27 \%)$ & $30(49 \%)$ & $4(50 \%)$ & $29(47 \%)$ \\
\hline \multicolumn{5}{|c|}{ Intensity of treatment rating (one rating per family) } \\
\hline 1 & & $2(3 \%)$ & & \\
\hline 2 & $6(58 \%)$ & $15(24 \%)$ & & \\
\hline 3 & $5(42 \%)$ & $38(60 \%)$ & & \\
\hline 4 & & $8(13 \%)$ & & \\
\hline
\end{tabular}

To ensure a representative sample, comparisons were made with the PRG on demographic variables, treatment intensity, and acute distress using Fisher's exact tests and independent sample t tests. Descriptive statistics for the immunology markers, specifically percent $\mathrm{NK}$ whole blood, absolute $\mathrm{NK}$ whole blood, $\mathrm{LU}_{20} / 10^{7}$ PBMC ( $\left.\mathrm{LU}_{20} \mathrm{PBMC}\right)$, and $\mathrm{LU}_{20} / 10^{7} \mathrm{NK}\left(\mathrm{LU}_{20} \mathrm{NK}\right)$ were completed. Distributions of $\mathrm{LU}_{20} \mathrm{PBMC}$ and $\mathrm{LU}_{20} \mathrm{NK}$ were compared between fathers and mothers and to the IRG using a Wilcoxon rank sum test. Nonparametric correlations (Spearman) were used to determine the association between the immunity markers and acute stress because the immunity markers were not normally distributed. A power analysis showed that we could detect a 0.80 correlation with $80 \%$ power with 10 participants. A sample of 20 is required to detect a correlation of 0.60 or stronger with $80 \%$ power.

\section{Results}

\section{Sample Description}

The sample consisted of 19 caregivers of 14 children ( 7 male, 7 female) with an age range of $1-16$ years (mean $=$ 6.6 years, $\mathrm{SD}=4.9$ years). In six families both caregivers participated, after one caregiver pair was removed from analyses. Mothers had a mean age of 35.8 years $(\mathrm{SD}=7.5$ years). Nearly all $(n=10)$ had graduated from high school and the majority $(n=7)$ were married. The mothers were predominantly Caucasian $(n=8)$. Fathers' mean age was 39.1 years ( $\mathrm{SD}=4.6$ years). All fathers reported completing high school and were married. Fathers were also predominantly Caucasian $(n=7)$. Approximately half of the families had an annual income over USD 50,000. No participant endorsed any of the health screening items of concern. The diagnoses of the children were: leukemia $(n=7)$, lymphoma $(n=4)$, and brain tumor $(n=3)$. There were no differences between this sample and the PRG on the demographic, cancer treatment intensity, or acute stress variables (table 1). ASDS scores for mothers and fathers (in this sample and the larger sample from which they were drawn) were elevated. Thirteen parents in our sample (62\%) met diagnostic criteria for ASD and seven mothers and six fathers had elevated ASDS scores.

Overall, the distributions for $\mathrm{LU}_{20}$ PBMC and $\mathrm{LU}_{20}$ NK were right-skewed with $50 \%$ of the $\mathrm{LU}_{20} \mathrm{PBMC}$ and $\mathrm{LU}_{20} \mathrm{NK}$ counts below 26.9 (units) and 303 cells/ $\mu$ l, respectively. Mothers on average had significantly lower percentage NK whole blood $(\mathrm{p}=0.02)$ and absolute NK whole blood $(p=0.01)$ values than fathers, with no significant differences seen between mothers and fathers on measures of $\mathrm{LU}_{20} \mathrm{NK}$ or $\mathrm{LU}_{20}$ PBMC (table 2). Mothers and fathers did not differ significantly from the IRG on $\mathrm{LU}_{20} \mathrm{NK}$ or $\mathrm{LU}_{20}$ PBMC ( $>$ > 0.05).

\section{Correlations between Psychological and Innate Immunity Markers}

There were no significant associations between acute stress and immune markers for mothers or fathers (mother median Spearman rho $=0.05$; father median Spearman rho $=0.15)$. 
Table 2. Acute stress and innate immune markers

\begin{tabular}{|c|c|c|c|c|c|}
\hline & Acute stress & $\% \mathrm{NK}$ & Absolute NK & $\mathrm{LU}_{20} \mathrm{PBMC}$ & $\mathrm{LU}_{20} \mathrm{NK}$ \\
\hline \multicolumn{6}{|l|}{ Mothers $(n=11)$} \\
\hline Mean $\pm S D$ & $52.5 \pm 21.2$ & $7.91 \pm 3.27$ & $153.18 \pm 75.27$ & $25.84 \pm 17.84$ & $325.23 \pm 219.10$ \\
\hline Range & $23-88$ & $4.65-16.43$ & $79-345$ & $\begin{array}{c}8.3-68.9 \\
(p=0.83)^{b}\end{array}$ & $\begin{array}{l}130.9-864.6 \\
(\mathrm{p}=0.38)^{\mathrm{b}}\end{array}$ \\
\hline \multicolumn{6}{|c|}{ Female IRG reference $^{\mathrm{a}}(\mathrm{n}=27)$} \\
\hline Mean $\pm S D$ & & & & $38.31 \pm 21.97$ & $566.27 \pm 343.87$ \\
\hline Range & & & & $4.08-228.62$ & $25.9-2,418.00$ \\
\hline \multicolumn{6}{|c|}{ Female PRG reference $(n=65)$} \\
\hline Mean $\pm \mathrm{SD}$ & $47.2 \pm 13.9$ & & & & \\
\hline Range & $23-82$ & & & & \\
\hline \multicolumn{6}{|l|}{ Fathers $(n=8)$} \\
\hline Mean $\pm S D$ & $44.6 \pm 8.5$ & $11.84 \pm 3.29$ & $240.63 \pm 67.05$ & $43.48 \pm 40.55$ & $378.55 \pm 225.54$ \\
\hline Range & $30-56$ & $7.17-18.83$ & $133-324$ & $\begin{array}{c}17-78.3 \\
(\mathrm{p}=0.78)^{\mathrm{c}}\end{array}$ & $\begin{array}{l}127.3-762.00 \\
(p=0.32)^{c}\end{array}$ \\
\hline \multicolumn{6}{|c|}{ Male IRG reference $^{\mathrm{a}}(\mathrm{n}=18)$} \\
\hline Mean \pm SD & & & & $56.72 \pm 21.36$ & $582.75 \pm 301.97$ \\
\hline Range & & & & $3.89-154.25$ & $46.9-1,834.90$ \\
\hline \multicolumn{6}{|c|}{ Male PRG reference $(n=63)$} \\
\hline Mean \pm SD & $47.2 \pm 14.9$ & & & & \\
\hline Range & $21-88$ & & & & \\
\hline
\end{tabular}

${ }^{a}$ Because there are multiple measurements available for the reference sample, mean 8 SD values were calculated as weighted average by combining individual-level statistics.

b Mothers vs. female IRG based on Wilcoxon rank sum tests.

${ }^{\mathrm{c}}$ Fathers vs. male IRG based on Wilcoxon rank sum tests.

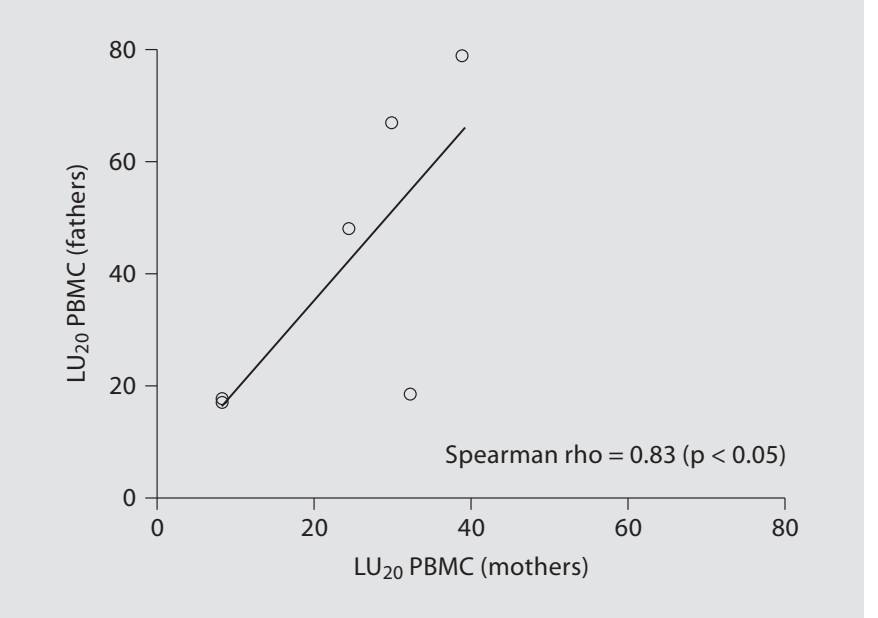

Fig. 1. Scatterplot of $\mathrm{LU}_{20}$ PBMC from six parental dyads. The solid line is the regression line.

\section{Correlations between Mothers and Fathers in the}

Same Family (Six Pairs)

Correlations between mothers and fathers within a family showed positive significant associations on measures of $\mathrm{LU}_{20}$ PBMC (Spearman rho $=0.83, \mathrm{p}<0.05$ ) and $\mathrm{LU}_{20} \mathrm{NK}($ Spearman rho $=0.83, \mathrm{p}<0.05)$ (fig. 1). Nonsignificant correlations were found between mothers and fathers within a family on measures of percent NK in whole blood, absolute NK cell numbers in whole blood and acute stress.

\section{Discussion}

Parents of children newly diagnosed with cancer are a highly distressed and potentially vulnerable group. In the hours and days after learning that their child has a lifethreatening illness, parents must make decisions about their child's treatment, continue to parent the child (and other siblings) and maintain the integrity of their couple relationship and family as they reorganize to accommo- 
date prolonged and intrusive treatments. In order to expand upon the psychological literature documenting parental distress, we studied innate immune function in mothers and fathers in the same family within 2 weeks of learning of their child's cancer diagnosis. Although the findings are unique and intriguing, the sample size is small and the data must be viewed with caution.

As expected, mothers and fathers of children newly diagnosed with cancer reported elevated levels of acute stress, with about $60 \%$ meeting diagnostic criteria for ASD. The sample was consistent with the broader sample from which it was drawn and also consistent in rates of acute stress with other samples of parents of pediatric oncology patients $[3,5]$. These caregivers had higher rates of ASD (62\%) than caregivers in a sample of parents of children admitted to the pediatric intensive care unit (32\%) [17]. Despite these elevated levels of self-reported distress, the data did not indicate impaired immune function, as measured by NK cell activity, between caregivers in the study and healthy adults (IRG). It is important to note that healthy adults in the IRG comparison group were not matched with the immunity sample on variables of age or ethnicity. No significant correlations between NK cell count by flow cytometry and function or acute stress were observed for mothers or fathers of these subjects. This differs from reports of inverse relationships between measures of psychosocial distress and immunity [20]; however, these responses may differ with different stressors [21, 22]. Parenting a child with a life-threatening illness consists of a series of potentially traumatic acute events (e.g., diagnosis, complications, admissions to the intensive care unit) while at the same time involving 'chronic' adaptations to provide the treatments and care necessary for survival. This sequence of events differs from ways in which immune function is typically understood in terms of acuity and chronicity [22]. It is possible that the chronic nature of caregiving for a child with cancer may impact immunity over time.

One of the most unique aspects of this report is the remarkably strong association between mothers' and fathers' immune function within the same family (dyad). The exploration of how immune function between intimate family members may be related is highly novel, but consistent with an understanding of stress responses interpersonally. Immunity has been related to marital conflict when a laboratory task was used to evoke disagreement [23]. At an individual level, marital conflict was associated with a redistribution of lymphocytes and changes in NK cell activity. More specifically NK cells increased during marital conflict and decreased signifi- cantly following the conflict. NK cytotoxicity also increased during the task [23]. These data were reported for individuals, however, and not dyads. When a child is diagnosed with cancer, multiple family members (especially parents) are exposed to this stressor simultaneously. Their reactions to the potentially traumatic event (diagnosis) and their efforts to cope with it over the subsequent hours, weeks and months are intertwined with the reactions and efforts of other family members. These preliminary data suggest that, even when self-reported responses on psychological measures do not show agreement between spouses, there may be commonalities in immune function responses in family members. The data are intriguing for potential long-term understanding of how stressors may influence parents' physical and emotional well-being as caregivers for their children with cancer or other potentially life-threatening pediatric conditions.

The small sample size in this study precludes further interpretation or conjecture. Gathering data from all participants concurrently would have strengthened the study design. However, given the uniqueness and challenges of studying immune function in samples exposed to a childrelated event, the data are noteworthy and signal the importance of studying immune function across individuals in the same family or another close social group.

\section{Acknowledgments}

This research was funded by a grant from the National Cancer Institute to A.E. Kazak (R01-CA88828). Additional support was provided by the University of Pennsylvania/The Children's Hospital of Philadelphia Clinical Translational Research Center (UL1-RR024134). The authors thank Drs. Alexandra Boeving, Melissa Alderfer, and Alyssa Rodriguez and the SCCIP-ND research assistants - Kristen Craig, Justin Hulbert, Portia Jones, Julia Kaal, and Ifigenia Mougianis. We also thank Nancy B. Tustin, Richard A. Tustin IIIrd, Dr. Donald E. Campbell and the Stokes Flow Cytometry Core Laboratory.

\section{References $\quad 1$ Kazak AE, Simms S, Alderfer MA, Rourke MT, Crump T, McClure K, Jones P, Rodri- guez A, Boeving CA, Hwang WT, Reilly A: Feasibility and preliminary outcomes from a pilot study of a brief psychological interven- tion for families of children newly diagnosed with cancer. J Pediatr Psychol 2005;30:644- 655 . \\ 2 Stuber ML, Shemesh E: Post-traumatic stress response to life-threatening illnesses in chil- dren and their parents. Child Adolesc Psy- chiatr Clin N Am 2006;15:597-609.}

Lutz Stehl/Kazak/Hwang/Pai/Reilly/ Douglas 
3 Kazak AE, Boeving CA, Alderfer MA, Hwang WT, Reilly A: Postraumatic stress symptoms during treatment in parents of children with cancer. J Clin Oncol 2005;23: 7405-7410.

4 American Psychiatric Association: DSM-IVTR: Diagnostic and Statistical Manual of Mental Disorders, ed 4. Washington, American Psychiatric Association, 2000.

5 Patiño-Fernández AM, Pai A, Alderfer MA, Hwang WT, Reilly A, Kazak AE: Acute stress in parents of children newly diagnosed with cancer. Pediatr Blood Cancer 2008;50:289292.

6 Starkweather AR, Witek-Janusek L, Nockels RP, Peterson J, Mathews HL: Immune function, pain, and psychological stress in patients undergoing spinal surgery. Spine 2006; 31:E641-E647.

7 Lutgendorf S, Sood AK, Anderson B, McGinn S, Maiseri H, Dao M, Sorosky JI, De Geest K, Ritchie J, Lubaroff D: Social support, psychological distress, and natural killer cell activity in ovarian cancer. J Clin Oncol 2005;23:7105-7113.

8 Douglas SD, Camarca M, Xu J, Durako S, Murphy D, Moscicki B, Wilson CM: The relationships between substance abuse, psychological variables, and natural killer cell enumeration and function in HIV-infected and high-risk uninfected adolescents. AIDS Res Hum Retroviruses 2003;19:399-408.
9 De Gucht V, Fischler B, Demanet C: Immune dysfunction associated with chronic professional stress in nurses. Psychiatry Res 1999; 85:105-111.

10 Arranz L, Guayerbas N, De la Fuente M: Impairment of several immune functions in anxious women. J Psychosom Res 2007;62: 1-8.

11 Kawamura N, Kim Y, Asukai N: Suppression of cellular immunity in men with a past history of posttraumatic stress disorder. Am J Psychiatry 2001;158:484-486.

12 Futterman AD, Wellisch DK, Zighelboim J, Luna-Raines M, Weiner H: Psychological and immunological reactions of family members to patients undergoing bone marrow transplantation. Psychosom Med 1996; 58:472-480.

13 Glaser R: Stress-associated immune dysregulation and its importance for human health: a personal history of psychoneuroimmunology. Brain Behav Immun 2005;19:3-11.

14 Kuster PA, Merkle CJ: Caregiving stress, immune function, and health: implications for research with parents of medically fragile children. Issues Compr Pediatr Nurs 2004; 27:257-276.

15 Bryant RA, Moulds ML, Guthrie RM: Acute Stress Disorder Scale: a self-report measure of acute stress disorder. Psychol Assess 2000; 12:61-68.

16 Auerbach SM, Kiesler DJ, Wartella J, Rausch S, Ward KR, Ivatury R: Optimism, satisfaction with needs met, interpersonal perceptions of the healthcare team, and emotional distress in patients' family members during critical care hospitalization. Am J Crit Care 2005;14:202-210.
17 Balluffi A, Kassam-Adams N, Kazak A, Tucker M, Dominguez T, Helfaer M: Traumatic stress in parents of children admitted to the pediatric intensive care unit. Pediatr Crit Care Med 2004;5:547-553.

18 Werba BE, Hobbie W, Kazak AE, Ittenbach RF, Reilly A, Meadows AT: Classifying the intensity of pediatric cancer treatment protocols: the Intensity of Treatment Rating Scale 2.0 (ITR-2). Pediatr Blood Cancer 2007; 48:673-677.

19 Douglas SD, Ho WZ, Gettes DR, Cnaan A, Zhao H, Leserman J, Petitto JM, Golden RN, Evans DL: Elevated substance P levels in HIV-infected men. AIDS 2001;15:20432045.

20 Motzer SA, Jarrett M, Heitkemper MM, Tsuji J: Natural killer cell function and psychological distress in women with and without irritable bowel syndrome. Biol Res Nurs 2002;4:31-42.

21 Irwin M, Hauger R, Patterson TL, Semple S, Ziegler M, Grant I: Alzheimer caregiver stress: basal natural killer cell activity, pituitary-adrenal cortical function, and sympathetic tone. Ann Behav Med 1997;19:83-90.

22 Segerstrom SC, Miller GE: Psychological stress and the human immune system: a meta-analytic study of 30 years of inquiry. Psychol Bull 2004;130:601-630.

23 Dopp JM, Miller GE, Myers HF, Fahey JL: Increased natural killer-cell mobilization and cytotoxicity during marital conflict. Brain Behav Immun 2000;14:10-26. 